\title{
Farklı Bağlayıcı ve Sinterleme Katkılarının SiC Seramik Prefom Mikroyapısı Üzerine Etkisi
}

\author{
${ }^{* 1}$ Ebru Y1lmaz and ${ }^{2}$ Fatih Çalışkan \\ Teknoloji Fakültesi, Metalurji ve Malzeme Mühendisliği, Sakarya Uygulamalı Bilimler Üniversitesi,Türkiye
}

\begin{abstract}
Özet
Metal döküm ürünlerinin mekanik özelliklerini belirleyen önemli kısımlardan birisi dökülen sıvı metalin kalıba girişi sırasında filtrasyonunun yapılmasıdır. Seramik filtre kullanımı, filtre edilen sıvı metalden üretilen ürünlerin daha düşük empürite içermesi sebebiyle hassas kullanım alanları için önemli arz etmektedir. $\mathrm{Bu}$ çalışmada, alüminyum matrisli kompozit üretiminde kullanılmak üzere silisyum karbür seramik preformların üretiminde farklı kimyasal katkı malzemeleriyle hazırlanan seramik çamurdan replikasyon yöntemi ile makroporoz seramik köpüklerin üretimi gereçekleştirilecektir. Ana malzeme olarak, partikül formda SiC, sıv1 faz oluşturucu katkı malzeme olarak MAS (magnezyum oksit, alüminyum oksit ve silika), stabilizör olarak ise silisik asit türevleri kullanılmıştır. Poliüretan kurban malzeme ile replika edilen seramik preform yapısı $>1000 \mathrm{C}$ sıcaklıklarda 1-3 saat süreyle sinterlenmiştir. Ürünler makrostereo mikroskopla morfolojik açıdan incelenmiştir. Mekanik özellikleri ise basma testi ile belirlenmiştir. Morfolojik inceleme sonuçları ve basma test verileri incelendiğinde en iyi sonuç 1BMAS18 kompozisyoundan elde edilmiştir.
\end{abstract}

Anahtar kelimeler: seramik filtre, silisyum karbür, replikasyon yöntemi

\section{The Effect of Different Binders and Sintering Additives on Microstructure of SiC Ceramic Prefom}

\author{
${ }^{* 1}$ Ebru Yılmaz and ${ }^{2}$ Fatih Çalışkan \\ Faculty of Technology, Department of Metallurgical and Materials Engineering, Sakarya University of Applied \\ Sciences, Turkey
}

\begin{abstract}
One of the most important points that determine the mechanical properties of metal casting products is the filtration of the poured liquid metal during the entry into the mold. The use of a ceramic filter is important for sensitive applications, as the products produced from the filtered liquid metal contain lower impurities. Aluminium matrix composites consist of $\mathrm{Al}$, silicon carbide ceramic preforms and different additives. It is to prepare with replication method. $\mathrm{SiC}$ in particulate form as main materials can be used in production of silicon carbide preform. Additive materials (magnesium oxide, aluminium oxide and silica) lead to liquid phase forming and silicic acid derivatives can be added as stabilizers. Polymeric replica daubed with the slurry was sintered at $\geq 1000^{\circ} \mathrm{C}$ temperatures for $1-3$ hours. The products were examined in terms of morphologically by macrostereo microscope. Mechanical properties of the ceramic preform were determined by compression test. When the test datas were handled, the best result was obtained from the 1BMAS18 coded preform.
\end{abstract}

Key words: ceramic filter, silicon carbide, replication method

*Corresponding author:Ebru Yilmaz Address: Faculty of Technology, Department of Metallurgical and Materials Engineering, Sakarya University of Applied Sciences, 54187, Sakarya, TURKEY. E-mail address: ebruyilmaz@subu.edu.tr, Phone: +902646160593 


\section{Giriş}

Köpükler, açık ve kapalı hücre olmak üzere iki tip hücresel yapıya sahiptir. Kapalı hücreli seramik köpükler genellikle 1sı yalıtımı ve yangın koruma uygulamaları için kullanılır. Açık hücreli seramik köpükler ise özellikle ergimiş metal filtrasyonu, dizel motor egzoz filtreleri ve sıcak gaz filtrasyonu için kullanılır [1]. Öte yandan, metal veya polimer matris kompozit üretiminde takviye malzemesi olarak da kullanımı yaygındır [2]. Makro-poroz seramik köpükler, genellikle toplam hacmin yaklaşık \%70 ile \%90 arasında geniş bir gözenek hacmine sahip seramik yapılardır. Ancak gözeneklerin genel morfolojisinde ve köpüklerin özelliklerinde farklılık gözlenmektedir. Seramik köpüklerde ana iskelet olarak silisyum karbür, alümina, zirkonya, silika yaygın kullanılmaktadır [1].

\subsection{Seramik Köpüklerin Üretim Yöntemleri}

Seramik köpüklerin üretim yöntemleri ise dört sınıfa ayrılabilir;

1. Kısmi sinterleme

2. Harcanan malzeme

3. Doğrudan köpükleştirme tekniği

4. Replikasyon yöntemi [3].

\subsubsection{Kısmi sinterleme}

Toz bileşenin kısmi sinterlenmesi, gözenekli seramik malzemeleri üretmek için en kolay yöntemdir. Bu yöntemle yoğun malzemeler elde etmek için gerekli sıcaklık ve sürelerde önemli miktarda düşüş sağlanabilir. Gözenekler, sinterlenme sıcaklığında toz partiküllerinin boyun vermesi sonucu, tozların arasında hapsolan boşluklardan meydana gelmektedir. Gözeneklilik derecesi, sinterleme işleminin optimize edilmesiyle kontrol edilebilir ve gözenek büyüklügü, ham maddenin başlangıç tanecik boyutuyla belirlenir [4]. Bu teknikle elde edilen gözenekli seramikler maksimum \%60 gözenekliliğe sahiptir [5].

\subsubsection{Harcanan malzeme}

Gözenekli seramikleri bu yöntemle elde edebilmek için yani gözenek oluşturması amacıyla uygun miktardaki kurban malzemeler sinterlemeden önce seramik toz içerisine karıştırıp sinterleme işlemi uygulanarak gözenekli yapı oluşturulur (Şekil 1.).

Sık kullanılan gözenek oluşturucu maddeler, polimer boncuklar, organik lifler, patates nişastası, grafit, kömür, salisilik asit, karbonil, kömür ve sıv1 parafindir. Gözenek oluşturan maddeler genellikle sentetik organik maddeler (polimer boncuklar, organik lifler, vb.), doğal organik maddeler (patates nişastası, selüloz, pamuk, vb.), metalik ve inorganik maddeler (nikel, karbon, 
uçucu kül, cam) olarak sınıflandırılır. Malzemelerin gözenekliliği, kurban malzemelerin miktarı ile kontrol edilebilir [6].

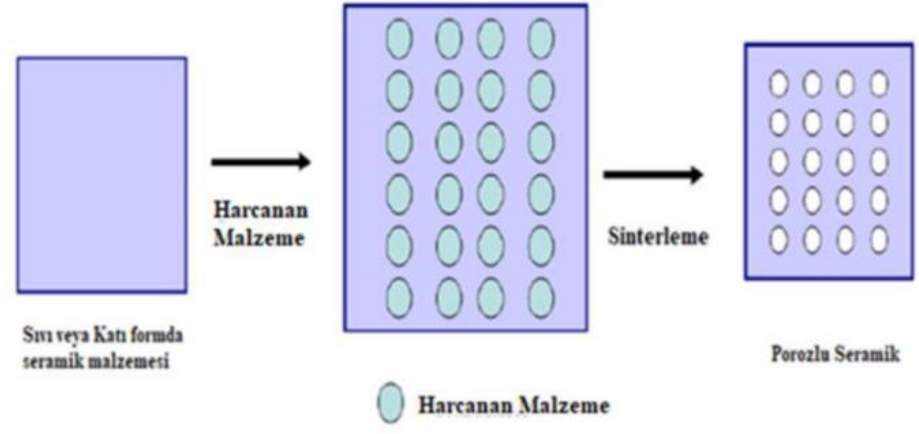

Şekil 1. Kurban şablon tekniğinin şematik görünümü [5].

\subsubsection{Doğrudan köpükleştirme tekniği}

Doğrudan köpükleştirme tekniği, \%45 ile \%97 arasında değişen gözenekliğe ve $1 \mathrm{~mm}$ ile $30 \mathrm{~mm}$ aralığındaki hücre boyutlarına sahip açık ve kapalı gözenekli yapıların üretimi için uygun bir yöntemdir [7]. Bu yöntemde, gözenekli malzemeler genellikle seramik çamurun içinde kabarcıklar oluşturularak elde edilir (Şekil 2.). Bu işlem mekanik çalkalama veya gazların in situ dönüşümü ile gerçekleştirilir. Daha sonra köpürtülen seramik çamur kurutulur ve sinterlenme işlemi uygulanarak yüksek mukavemetli gözenekli bir yapı elde edilmektedir [3].

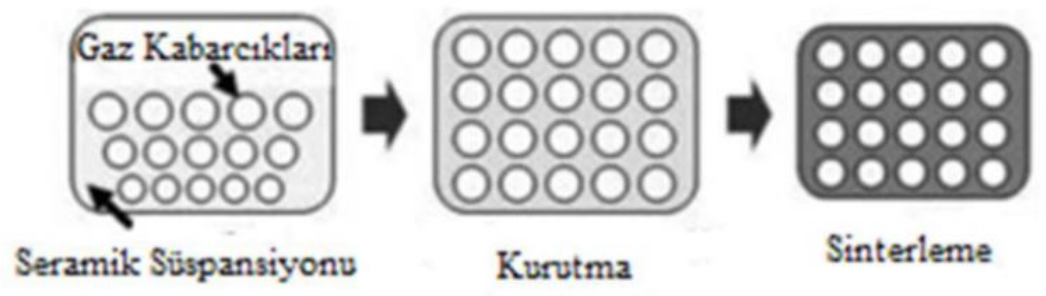

Şekil 2. Direk köpükleştirme tekniğinin şematik görünümü [3].

\subsubsection{Replikasyon yöntemi}

Organik köpük emdirme işlemi Schwartzwalder ve Somers tarafından 1963 yılında ortaya çıkmıştır [8]. İlk üretim yöntemlerinden biri olup, hala endüstride en yaygın olarak kullanılan makro-poroz seramik köpük üretim işlemidir. Bu üretim işlemi açık hücreli bir polimer köpüğünün seramik çamurlar ile kaplanmasını içerir. Fazla çamurun polimerden uzaklaştırılması, akabinde sinterlenmesi ve polimer yanması sonucu seramik köpük tek bir aşamada üretilir.

$\mathrm{Bu}$ yöntemde altlık malzeme seçimi için farklı polimer malzemesi olarak poliüretan (PU), poli(vinil klorür) (PVC), polistiren (PS) ve selüloz kullanılmaktadır. Organik köpügün özelliklerinin tekrarlanabilirliği son derece önemlidir. Sıkıştırıldıktan sonra geriye dönebilmelidir. Son olarak, sinterleme işlemi sonunda seramik köpüğe zarar vermeden temiz ve tamamen yanması gerekir. 
Örnek olarak, Amerika Birleşik Devletin'deki Selee Corp, organik altlık malzeme olarak \%97 boşluk hacmine sahip birbirine bağlı, açık hücreli bir poliüretan köpüğü kullanır. Bu yapı, üç boyutlu olarak tekrarlanan dodekadehedra karmaşık bir desenden oluşur.

Seramik çamur hazır olduğunda polimer köpüğe emdirilme işlemi yapılıp poliüretanın yüzeyleri kaplanır. Köpük çamurun içine daldırılır ve sıkıştırılarak havası alınır. Hala seramik çamurun içindeyken, köpüğün yeniden genleşmesine izin verilir ve bu çamur köpüğün açı hücrelerine doğru emilir. İstenilen kaplama yoğunluğunu elde etmek için bu aşama birkaç kez tekrar edilebilir.

Köpük uygun bir şekilde kaplandığında, bir fırında kurutulur ve seramik yapıya dönüştürülür. Daha sonra organik katkıları seramik çamurdan uzaklaştırmanın yanı sıra seramik kolların içindeki polimerin yakılması için sinterleme işlemine maruz birakılır. Sinterleme işleminin sonucunda üretilmiş nihai seramik köpük Şekil 3.'de gösterilmektedir [9].

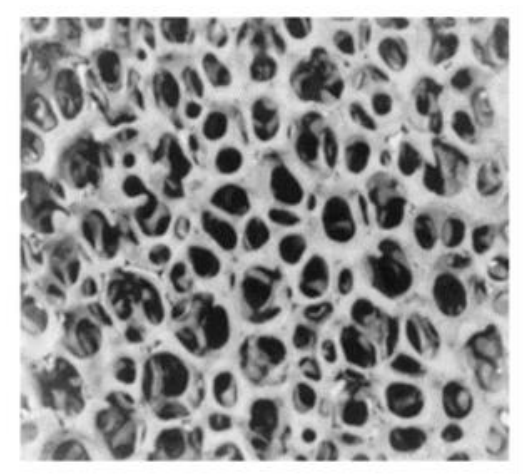

Şekil 3. Replikasyon yöntemi üretilmiş nihai seramik köpük [9].

Bununla birlikte, bu üretim yönteminde istenmeyen bir kusur ortaya çıar. Polimer altlık malzemenin pirolizi sırasında polimer yanar ve polimerin tepe noktalarında Şekil 4.'de görülen üçgensel bir boşluk ile seramik köpügün kollarında çatlaklar oluşur. Bu tür kusurlar gözenekli seramiklerin nihai mekanik özellikleri üzerinde olumsuz etkiye sahip olacaktır [5]. Seramik köpüğün yoğunluğunu ve mukavemetini sağlamak için de bir sinterleme çizelgesine ihtiyaç duyulur. Gerekli koşullar, kullanılan seramik malzemenin bileşimine bağlıdır [9].

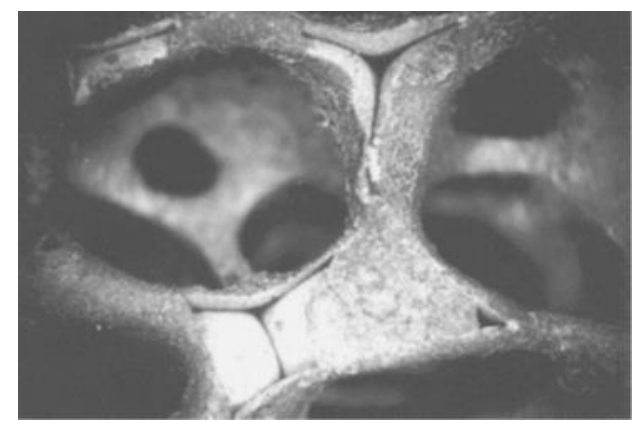

Şekil 4. Seramik köpük üretiminde açığa çıkan kusur (üçgensel bölge) [9].

\section{Deneysel çalışmalar}


Silisyum karbür esaslı preform seramik filtre üretiminde ana iskelet yapıyı oluşturan 10 PPI poliüretan süngerler Kurtoğlu Filtre Otomotiv Paz. San. Tic.Ltd. Şti' den temin edilerek üretilmiştir. Replikasyon yöntemi ile üretilen seramik köpüklerin ana iskelet yapısını $\mathrm{SiC}$ ve Bentonit tozu malzemesi oluşturmuştur. Bağlayıcı kullanarak şekillendirilen ve nihai ürünün ana yapısında olması istenen silisyum karbür tozları Fetaş Alüminyum firmasından temin edilmiştir. Koloidal özelliği ve yüksek plastisitise nedeniyle bağlayıcı olarak kullanılan bentonit tozu ise Karakaya Bentonit A.Ş. Ankara'dan temin edilmiştir.

\subsection{Reçetenin hazırlanması}

Seramik çamur için hazırladığımız numuneler kullanılan bağlayıcı ve malzeme cinsine ve miktarlarına göre sınıflandırılmış ve kodlar verilmiştir. Bu kodlar; hazırlanan SiC seramik çamur içine kattığımız malzemeler bentonit, magnezyumoksit, alüminyumoksit ve silika olan malzeme cinsine göre adlandırılmaktadır. Ağırlıkça sadece bentonit SiC tozuna eklediğinde $1 \mathrm{~B}$ ve bu 1B seramik çamurun içine ağırlıkça magnezyumoksit, alüminyumoksit ve silika (MAS) eklediğimizde 1BMAS olduğunu belirtmektedir. Bu kodların sonunda bulunan 18 rakamı ise hazırlanan çamurun içindeki ağırlıkça formülize edilmiş silisik asit yüzdesini göstermektedir. Hazırlanan seramik çamurlarının bileşimleri Tablo 1'de gösterilmektedir.

Tablo 1. Seramik çamurlarının içindeki malzemelerin ağırlıkça katkı oranları

\begin{tabular}{|c|c|c|c|c|}
\hline & $\begin{array}{l}\text { Bentonit } \\
\text { Ăg. \% }\end{array}$ & SiC Ăg. \% & 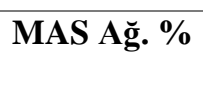 & $\begin{array}{c}\text { Formülize edilmiş silisik } \\
\text { asit Ă̆. \% }\end{array}$ \\
\hline 1B & $5-30$ & 70-95 & & \\
\hline 1BMAS & $5-25$ & $65-90$ & 5 & \\
\hline 1BMAS18 & $5-20$ & $45-75$ & 5 & 18 \\
\hline
\end{tabular}

(Sıvı faz oluşumu sırasında hacimsel değişimler hesaba katılmamıştır).

\subsection{Seramik çamurun hazırlanması}

Deneysel çalışmada Tablo 1.' de belirtilen karışımlar hassas terazide tartım yapıldıktan sonra seramik havanda bağlayıcı özelliğindeki bentonit tozu, ana iskeleti oluşturan $\mathrm{SiC}$ tozu, mukavemet arttırıcı MAS tozları ve kararlı bir yapı meydana getirmek için formülize edilmiş silisik asit eklenerek saf su yardımıyla seramik çamura akışkanlık sağlayarak poliüretan süngere emdirilme işlemi yapılmaktadır (Şekil 5.). 


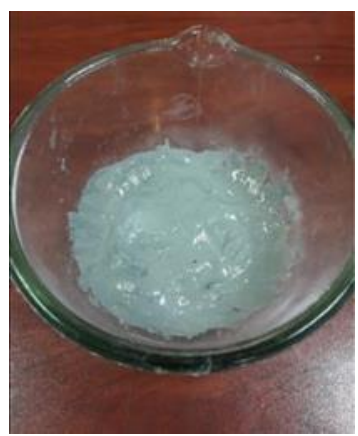

Şekil 5. Hazırlanan seramik çamur

Deneyler boyunca 3 farklı numune hazırlanmış ve bu numunelerin tamamına aynı sinterleme işlemleri uygulanmıştır. Fırına konulan malzemeler atmosfer kontrollü yatay tüp firında $>1000{ }^{\circ} \mathrm{C}$ sıcaklıkta $90 \mathrm{dk}$ sinterlenme işlemine tabi tutulmuştur. Bu işlemin ardından firın kapatılmış ve numunelerin oda sıcaklığına soğutulması işlemi yavaş bir şekilde gerçekleştirilmiştir. Sinterlenen numunelere ait görüntü Şekil 6.'da gösterilmektedir.

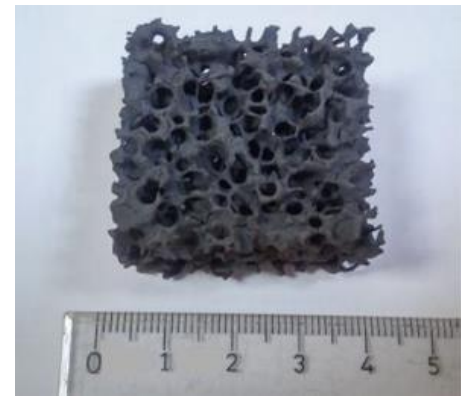

Şekil 6. Sinterlenmiş seramik köpük

\subsection{Makro stereo incelemeleri}

10 ppi'lık seramik köpük üretiminde, seramik çamura katılan katkı malzemelerinin etkisi Makro stereo görüntüleri üzerinde incelenmiştir.

\subsubsection{Katkı malzemelerin seramik köpüğ̈̈n mikroyapısı üzerindeki etkisi}

Farklı katkı malzemeleri kullanılarak üretilen 1B, 1BMAS ve 1BMAS18 kodlu seramik köpüklerin makro görüntüleri Şekil 7.'de verilmiştir. 


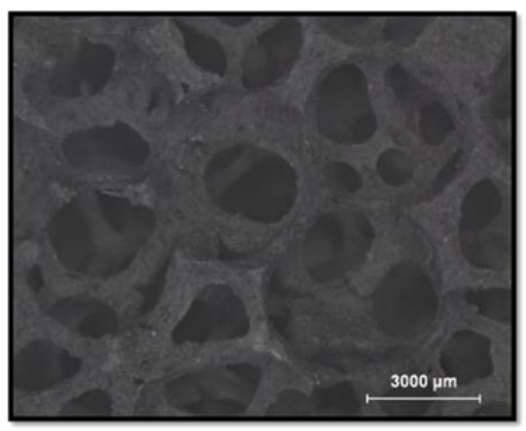

(a)

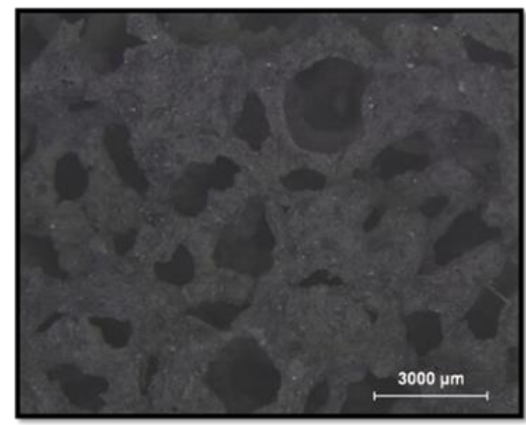

(b)

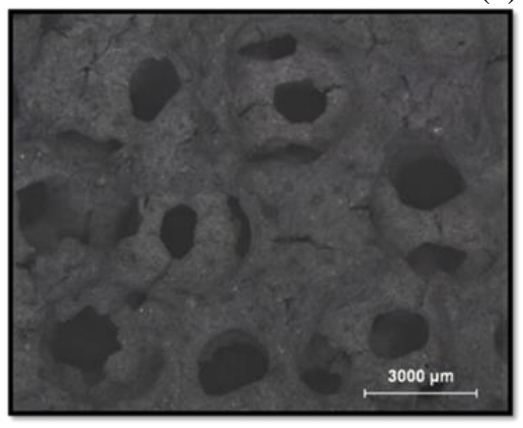

(c)

Şekil 7. 1B (a), 1BMAS (b) ve 1BMAS18 (c) kodlu seramik köpüklerin makro stereo görüntüleri

Yao ve arkadaşları $\mathrm{SiC}$ seramik köpük üretiminde $\mathrm{MgO}-\mathrm{Al}_{2} \mathrm{O}_{3}-\mathrm{SiO}_{2}$ katk1 malzemelerini kullanarak replikasyon yöntemi ile üretmiştir. Seramik köpük üretiminde kullanılan optimum sıcaklığı $1300{ }^{\circ} \mathrm{C}$ sicaklık olarak belirtmektedir [10]. Yapılan çalışmada replikasyon yöntemi kullanılarak $1200{ }^{\circ} \mathrm{C}$ sicaklıkta elde edilen SiC seramik köpüklerde seramik çamurun içinde bulunan katk1 malzemelerinden sodyum alüminat bileşiğine $\mathrm{MgO}-\mathrm{Al}_{2} \mathrm{O}_{3}-\mathrm{SiO}_{2}$ katk1 malzemeleri ilave edilerek üretilen seramik köpüğün hücre kolları ve duvarlarında et kalınlığı oluşturulması başarılı bir şekilde gerçekleştirilmiştir. Seramik çamura katılan katkı malzemelerinde uygun parametre olarak 1BMAS18 seramik köpüğü eldesinin sonuçlarının iyi olduğu gözlenmektedir. 1B seramik köpügünün hücre kolları homojen olarak kaplandığı fakat MAS bileşiği katıldığında aglomerasyonlar meydana geldiği gözlenmektedir. Daha sonra formülize edilmiş silisik asit katk1 malzemesi eklenmesiyle 1BMAS18 kodlu seramik köpük olan yapının hücre kollarında yeterli bir kaplama miktarına sahip, geometrik şekli korunan ve açık gözenekli seramik köpük meydana geldiği Şekil 7.'de gözlenmektedir. Kumar ve arkadaşları farklı bir çalışmayla kapalı gözenekli $\mathrm{SiC}$ seramik köpük üretiminde epoksi kaplanmış polikarbosilan içindeki epoksi miktarına göre kapalı gözenekli seramik köpük üretmişlerdir [11]. Deneysel çalışma kapsamında replikasyon yöntemi ile $\mathrm{SiC}$ köpük üretiminde açık gözenekli seramik köpük üretimi gerçekleştirilmiştir. Liang ve arkadaşları çalışmalarında replikasyon yöntemi ile $\mathrm{SiC}$ seramik köpük üretip daha sonra üretilen $\mathrm{SiC}$ seramik köpüğe vakumlu ortamda, tekrardan hazırlanan alümina seramik çamuruna daldırarak infiltre edilip sinterleme işlemi $1450{ }^{\circ} \mathrm{C}$ sicaklıkta uygulanarak nihai ürünü elde etmişlerdir. Yaptığımız çalışmada ise seramik köpük üretiminde tek aşamada seramik çamurun içine SiC ve alümina dişında magnezyum oksit, silika ve formülize edilmiş silisik asit ilave ederek seramik çamur hazırlanılmıştır. Hazırlanan seramik çamur poliüretan süngere emdirilmesiyle $1200{ }^{\circ} \mathrm{C}$ 
sinterlenme işlemi gerçekleştirerek mukavemet değerlerinde başarılı bir sonuca ulaşılarak daha düşük bir sıcaklıkta nihai ürüne ulaşımı gerçekleştirilmiştir [12].

\subsubsection{Ppi’llk seramik köpüğ̈̈̈n EDS analiz sonucu}

1BMAS18 kodlu seramik köpükte bulunan magnezyum elementinin seramik çamura MAS bileşiğinin eklenmesi sonucu EDS analiz sonuçlarında yansıdığının bir göstergesidir. Ayrıca silisyum elementinin oranının yükselmesi 1BMAS18 seramik köpüğün içeriğindeki Silika ve Silisik asitten dolayı ortaya çıktığını göstermektedir. Fe elementinin varlığı ise Sodyum alüminat bileşiğinden meydana gelmektedir (Şekil 8.).

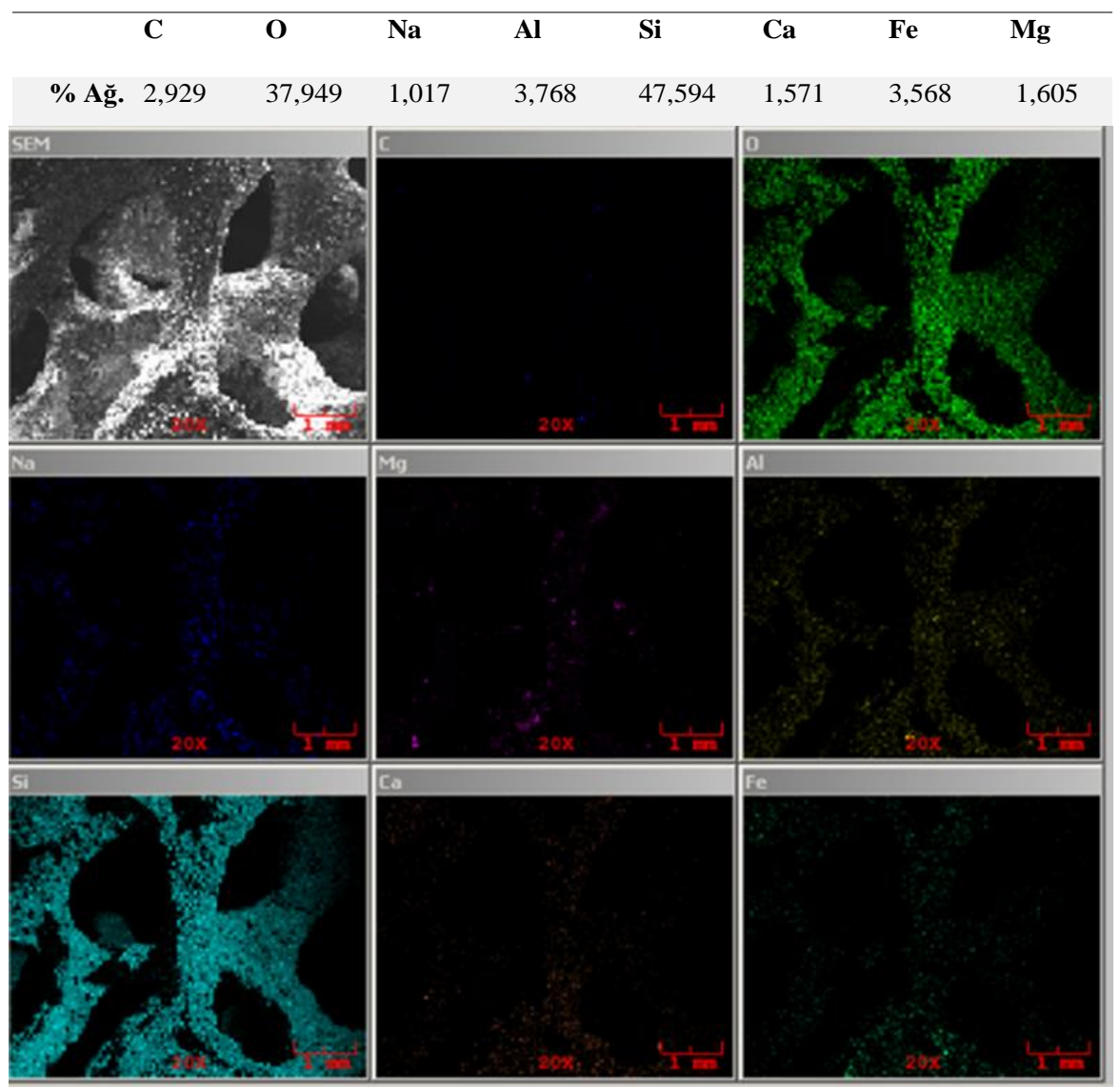

Şekil 8. 1BMAS18 kodlu seramik köpüğün kimyasal bileşimi ve Map EDS analiz sonucu

\subsubsection{Ppi’lı seramik köpüğ̈̈̈n basma test analiz sonuçları}

Katkı malzemeleri, hazırlanan seramik çamura eklemesiyle üretilmesi amaçlanıp seramik köpüklerin basma mukavemetleri kıyaslanmıştır. Katkı malzemelerinden sadece bentonit tozunun olduğu 1B kodlu seramik köpüğün hücre kolları ve duvarları yeteri kalınlığa ulaşılmamıştır. MAS bileşikleri ise çamurun akışkanlığını olumsuz yönde etkileyip aglomerasyona sebep olup strut yapıda çatlaklar oluşturmuştur. Aglomerasyonları engellemek için ise, formülize edilmiş silisik asitin seramik çamura katılmasıyla seramik köpüğün mukavemet artışına sebep vermiştir (Şekil 
9.). Bu sebeple optimum seramik köpük üretimi 1BMAS18 seramik köpük olup mukavemet değeri 145 N'dur.

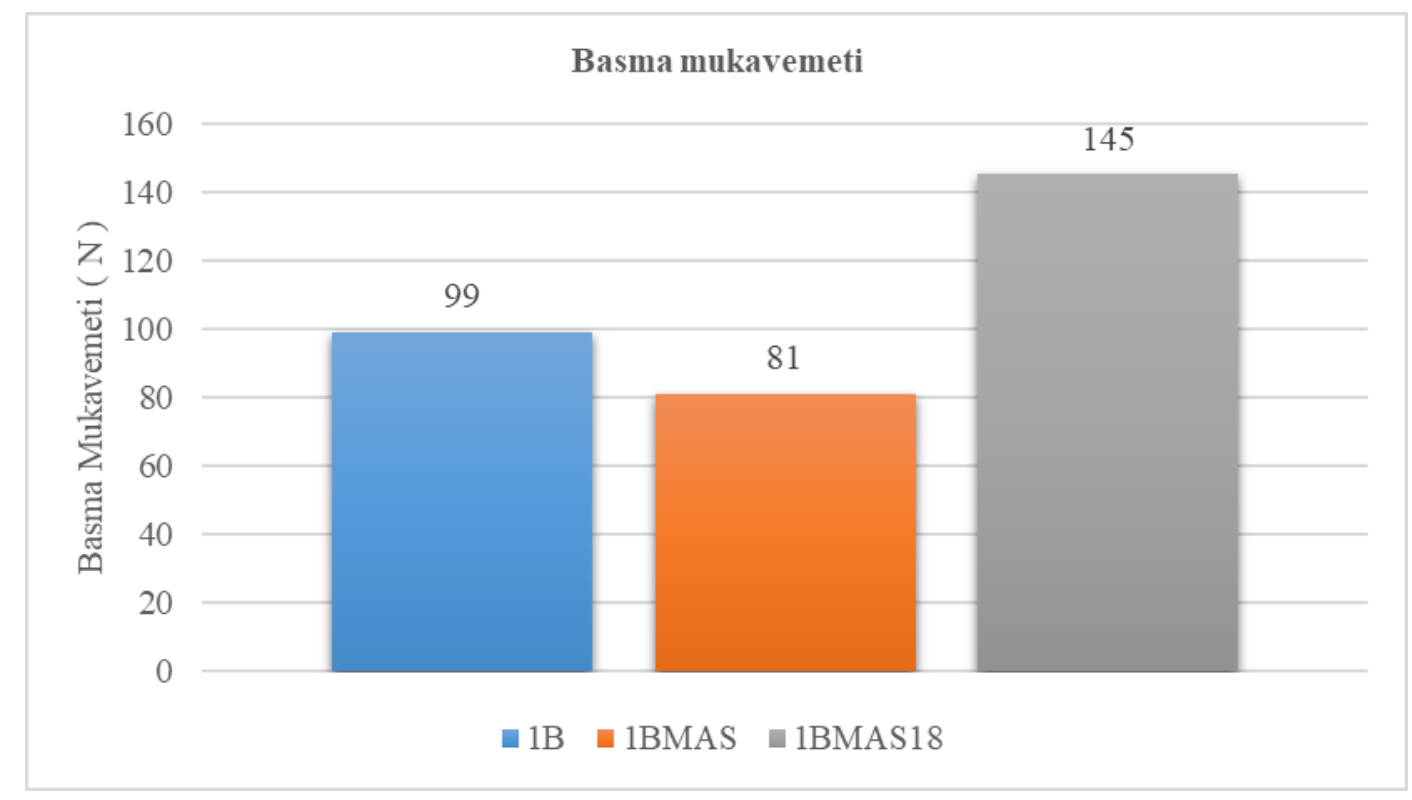

Şekil 9. 1B, 1BMAS ve 1BMAS18 seramik köpüklerin basma mukavemet değerleri

\section{Sonuçlar}

Farklı kompozisyonlara sahip 1B, 1BMAS ve 1BMAS18 kodlu seramik köpüklerin, farklı katkı malzemelerin sinterleme ve proses üzerine etkisi incelenmiştir. Replikasyon yöntemiyle üretilen seramik köpüklerin morfolojik yapıları geometrik şeklini korumuş olup hücre duvarları ve kolları yeterli bir kalınlığa ulaşılmıştır. Seramik köpüğün içindeki katkı malzemelerin varlığını teşkil etmek için Map-EDS yapıldı. Bunun sonuncunda seramik köpüklerde yüksek oranda silisyum elementinin bulunması, hem MAS bileşiğinden hem de formülize ettiğimiz silisik asittten meydana geldiği görülmektedir. 1BMAS18 kodlu seramik preform optimum olup basma mukavemet değeri ise $145 \mathrm{~N}$ elde edilmiştir.

\section{Referanslar}

[1] Ahmad, S., Latif, M. A., Taib, H., ve Ismail, A. F. (2013). Short review: Ceramic foam fabrication techniques for wastewater treatment application. In Advanced Materials Research Vol. 795, pp. 5-8. Trans Tech Publications.

[2] Colombo, P. (2005). Conventional and novel processing methods for cellular ceramics. Philosophical Transactions of the Royal Society A: Mathematical, Physical and Engineering Sciences, 364(1838), 109-124.

[3] Ahmad, R., Ha, J. H., ve Song, I. H. (2014). Processing methods for the preparation of porous ceramics. J Kor Powd Met Inst, 21(5), 389-98. 
[4] Jean, G., Sciamanna, V., Demuynck, M., Cambier, F., ve Gonon, M. (2014). Macroporous ceramics: Novel route using partial sintering of alumina-powder agglomerates obtained by spray-drying. Ceramics International, 40(7), 10197-10203.

[5] Liu, G. (2011). Fabrication of porous ceramics and composites by a novel freeze casting process (Doctoral dissertation, University of Birmingham).

[6] Ohji, T. (2013). Porous Ceramic Materials, Handbook of Advanced Ceramics, 1131-1143

[7] Gonzenbach, U. T., Studart, A. R., Tervoort, E., ve Gauckler, L. J. (2007). Macroporous ceramics from particle-stabilized wet foams. Journal of the American Ceramic Society, 90(1), 16-22.

[8] Karl, S., ve Somers, A. V. (1963). U.S. Patent No. 3,090,094. Washington, DC: U.S. Patent and Trademark Office.

[9] Scheffler, M., ve Colombo, P. (2005). Cellular ceramics. Structure, Manufacturing, Properties and Applications, 670.

[10] Yao, X., Tan, S., Zhang, X., Huang, Z., ve Jiang, D. (2007). Low-temperature sintering of $\mathrm{SiC}$ reticulated porous ceramics with $\mathrm{MgO}-\mathrm{Al}_{2} \mathrm{O}_{3}-\mathrm{SiO}_{2}$ additives as sintering aids. Journal of materials science, 42(13), 4960-4966.

[11] Mishra, M. K., Kumar, S., Ranjan, A., ve Prasad, N. E. (2018). Processing, properties and microstructure of $\mathrm{SiC}$ foam derived from epoxy-modified polycarbosilane. Ceramics International, 44(2), 1859-1867.

[12] Liang, X., Li, Y., Liu, J., Sang, S., Chen, Y., Li, B., ve Aneziris, C. G. (2016). Fabrication of $\mathrm{SiC}$ reticulated porous ceramics with multi-layered struts for porous media combustion. Ceramics International, 42(11), 13091-13097. 